\title{
Comparative Studies of Control Technique in Dynamic Voltage Restorer for Power Quality Improvement
}

\author{
Shaik Babul Saheb ${ }^{1}$, Nakka NarasimhaRao ${ }^{2}$ \\ ${ }^{1}$ M.Tech scholar, QIS College of Engineering \& Technology, Ongole, JNTU Kakinada, India \\ ${ }^{2}$ Assistant professor, QIS College of Engineering \& Technology, Ongole, JNTU Kakinada, India
}

\begin{abstract}
Power quality is one of the most important worry in the present power system. When the voltage sag, voltage swell, harmonic content etc., occurs then the key effect on the industrial consumer loads. To manage these events several custom power apparatuses are used. DVR is the power apparatus is utilized to improve the voltage stability i.e., to control the power quality situations in the power system. DVR is a custom power device used for mitigation of voltage sag, voltage swell. DVR is the grouping of voltage source inverter (VSI), booster transformer, filter and a DC energy source. DVR is to add voltage in series and in synchronism with the normal voltages to give back the voltage influences and improving power quality. There is several control techniques are presented for the operation of DVR. Here space vector PWM (SVPWM) control technique is used to produce the switching pulses for DVR. The projected system is designed in MATLAB software and the result shows the significance of DVR for better power quality in distribution systems.
\end{abstract}

Keywords: power quality, custom power devices, Voltage source inverter, DVR, control techniques for DVR, space vector PWM control, MATLAB.

\section{Introduction}

Today's world has become typically dependent upon the constant availability of electrical power. Commercial power accurately enables today's contemporary world to function at its busy pace. Many problems associated with the commercial power grid, which with its thousands of kms of transmission is subjected to weather circumstances like hurricanes, lightening storms, snow, ice and floods along with equipment failure, and switching operations. Power quality may effect due to these disturbances and there may be change in the power constraints like voltage, current, or frequency. Today's economical and contest between utilities. The problem associated with the power quality is more important. Voltage sag is the short drop in the voltage waveform. This depends upon amplitude and time.

Now a day's more attention on the distribution system to improve power quality, these devices are modified and known as custom power devices. The term custom power describes the value added power to the electrical utilities will offer to their customers. The main custom power devices which are used In distribution systems for power quality improvement are Distributed Static Synchronous Compensator (DSTATCOM), Dynamic voltage restorer (DVR), Active Filters (AF), Unified Power Quality Conditioner (UPFC), Surge Arresters (SA). These custom power devices were first proposed by N.G.Hingirani. DVR can solve the problems like voltage sag, voltage swell, and power factor correction harmonics.

In this paper space vector pulse width modulation technique is used for controlling the generation of switching pulses for the inverter of DVR.

\section{Dynamic Voltage Restorer}

DVR is primary application to compensate for voltage sags and swells. However the control techniques are different. Also, a DVR is expected to respond fast and they utilize PWM converters with IGBT or IGCT devices. The first DVR entered into the commercial service on the Duke Power System in USA. DVR can inject the voltage in each phase of necessary magnitude and phase. DVR response for the voltage changes is very fast it is in the order of milliseconds.

\subsection{Design requirements for DVR:}

DVR is commonly connected in series with the line to boost the drooped voltage through the boost or injection transformers. It can also eliminate the harmonics.

2.1.1. Switching apparatus: There are 4 main types of switching devices MOSFET's, GTO's, IGBT's, IGCT's. Each type has its own benefits and drawbacks.

2.1.2. Booster transformer: The transformer size depends on the saturation. To minimize the saturation, coupling transformer is required as a part of DVR. The total device cost depends on the transformer cost.

2.1.3. Supply side transformer: It is important to detect the supply side disturbances very accurately. It is main task for the operation of DVR.

2.1.4. Voltage restoration: At the time of restoration, for the voltage injection the DC link voltage maintained at correct level. So, DC capacitor bank is used.

2.1.5. Voltage control: Voltage control should be provided in such a way that it control the DVR system parameters.

Volume 4 Issue 11, November 2015 


\section{International Journal of Science and Research (IJSR) \\ ISSN (Online): 2319-7064}

Index Copernicus Value (2013): 6.14 | Impact Factor (2014): 5.611

\subsection{General structure of DVR:}

The following figure shows the general structure of DVR The power circuit of DVR has the following components

\subsubsection{Boost or injection transformer:}

The power is transferred to secondary side with the help of booster transformer.

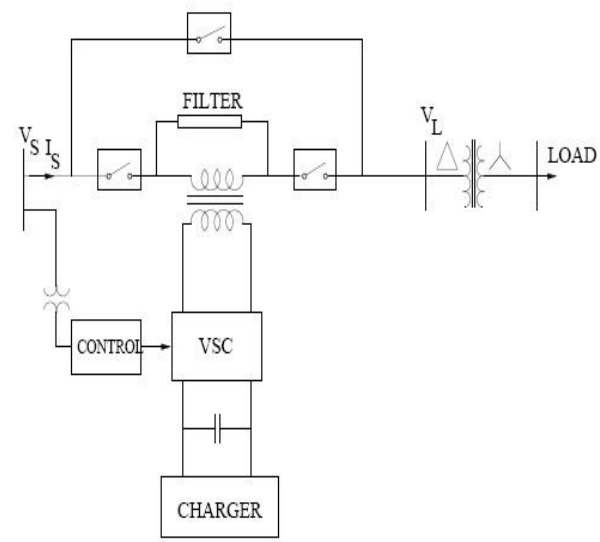

Figure 1: general structure of DVR

\subsubsection{Filters}

The harmonic contents generated in the pulse width modulation can be eliminated by using filters.

\subsubsection{Voltage source converter}

Voltage source converter is power electronics system and associated with storage device and switching devices, which can generates a sinusoidal voltage at any required frequency, magnitude, and phase angle. Here we are converting DC voltage waveform to $\mathrm{AC}$ voltage waveform.

\subsubsection{Storage device}

This device is required to supply active power to the load at the time of deep voltage sags. It is used to supply required energy for generation of injection voltage to voltage source converter via DC link.

\subsubsection{Capacitor}

DVR has the capacitor with large rating. It provides proper DC voltage as a input for voltage source converter.

\subsection{Working of DVR}

There are three types of working modes i.e., Protection mode, Standby mode, Boost mode of operation for dynamic voltage restorer

\subsubsection{Protection mode:}

In this mode of operation, if the current on the load side exceeds a tolerable limit due to any fault or short circuit on the load, DVR will isolate from the system

\subsubsection{Standby mode:}

In this mode of operation, the voltage winding of the injection transformer is short circuited through converter.

\subsubsection{Injection/Boost mode:}

In this mode of operation the DVR is injecting a compensating voltage through the injection transformer due to the detection of a disturbance in the supply voltage.

\section{Space Vector Pulse Width Modulation}

The control of DVR is relates with the finding of voltage sag, swell and injecting voltage.

\section{Structure of DVR by using space vector PWM}

Following figure give details about the control diagram of DVR with space vector PWM control technique. It consists of inverter, storage device, booster/injection transformer and space vector PWM controller. SVPWM controller requires two signals one is from supply side and other is from. By comparing these two signals and produce switching pattern booster/injection transformer which is voltage injected by the DVR.

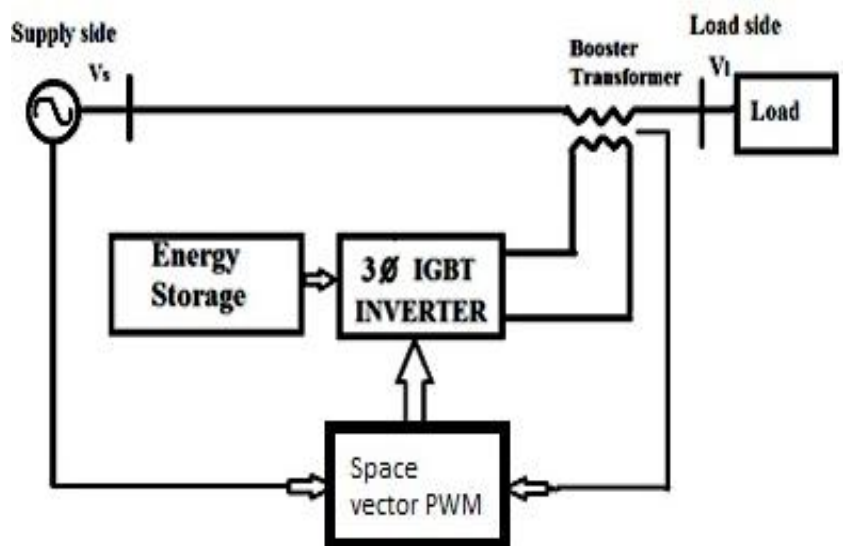

Figure 2: structure of DVR with space vector PWM control technique.

The space vector PWM generation module recognizes the modulation index command and generates the proper gate drive waveforms for each PWM cycle. A three phase 2 level inverter with dc link can have eight possible switching states, which produces output voltage of the inverter. Each inverter switching state generate a voltage space vector (V1 to V6 active vectors, V7 and V8 zero voltage vectors) in the space vector plane.

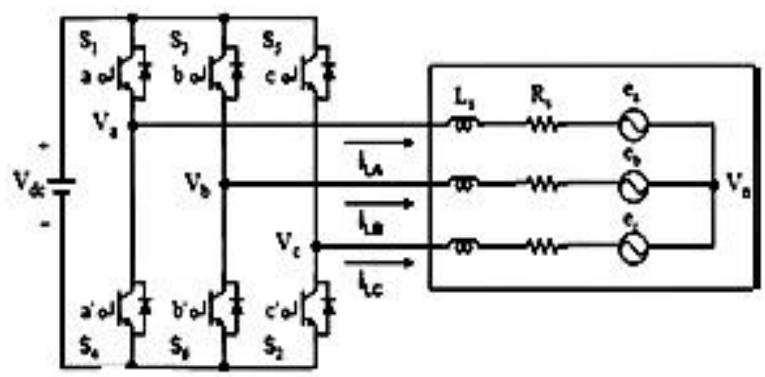

Figure 3: Three Phase voltage source PWM inverter

$\mathrm{S} 1$ to $\mathrm{S} 6$ are the six power switches that shape the output, which are prohibited by the switching variables a, a', b, b', c and $c^{\prime}$. When an upper transistor is switched on, i.e., when a, $\mathrm{b}$ or $\mathrm{c}$ is 1 , the corresponding lower transistor is switched off,

\section{Volume 4 Issue 11, November 2015}




\section{International Journal of Science and Research (IJSR) \\ ISSN (Online): 2319-7064 \\ Index Copernicus Value (2013): 6.14 | Impact Factor (2014): 5.611}

i.e., the corresponding $\mathrm{a}^{\prime}, \mathrm{b}^{\prime}$ or $\mathrm{c}^{\prime}$ is 0 . The relationship between the switching variable vector $[a, b, c] t$ and the lineto line voltage.

Vector [ $\mathrm{Vab} \mathrm{Vbc} \mathrm{Vca}]^{\mathrm{t}}$ is given in the following:

$$
\begin{aligned}
& V a b \\
& V b c
\end{aligned}=V d c\left[\begin{array}{ccc}
1 & -1 & 0 \\
0 & 1 & -1 \\
-1 & 0 & 1
\end{array}\right]\left[\begin{array}{l}
a \\
b \\
c
\end{array}\right]
$$

Also, the relationship between the switching uneven vector $[\mathrm{a}, \mathrm{b}, \mathrm{c}] \mathrm{t}$ and the phase voltage vector $[\mathrm{Va} \mathrm{Vb} \mathrm{Vc}]^{\mathrm{t}}$ can be expressed below.

$$
\begin{aligned}
& V a n \\
& V b n
\end{aligned}=\frac{\text { Wac }}{a}\left[\begin{array}{ccc}
2 & -1 & -1 \\
-1 & 2 & -1 \\
-1 & -1 & 2
\end{array}\right]\left[\begin{array}{l}
a \\
b \\
c
\end{array}\right]
$$

To apply the space vector PWM, the voltage equations in abc frame can be transferred into dq reference frame.

The purpose of space vector PWM technique is to estimate the reference voltage vector Vref using the eight switching patterns.

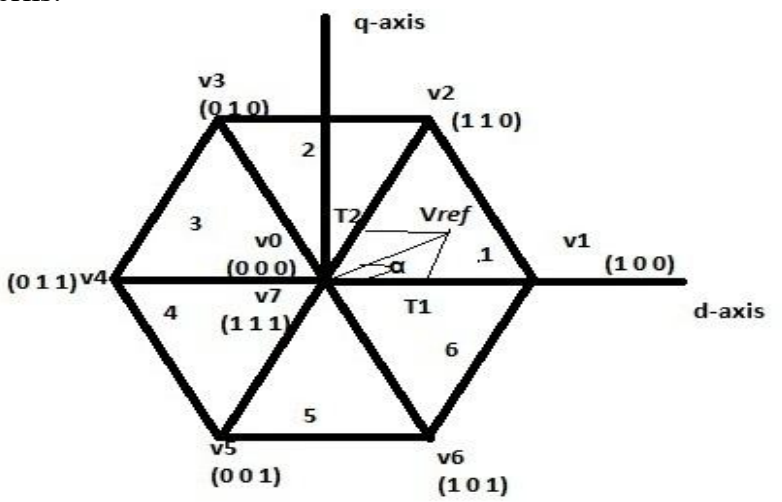

Figure4: switching vectors and sectors.

One simple method of estimation is to produce the average output of the inverter in a small period, $\mathrm{T}$ to be the same as that of Vref in the same period.

Space vector PWM can be implemented by the following steps:

Step 1. Determine Vd, Vq, Vref, and angle $(\alpha)$

Step 2. Determine time duration T1, T2, T0

Step 3. Determine the switching time of each transistor (S1 to S6)

Step1: Determine Vd, Vq, Vref, and angle ( $\alpha$ )

$$
\begin{aligned}
& {\left[\begin{array}{l}
\mathrm{Vd} \\
\mathrm{Vq}
\end{array}\right]=2 / 3\left[\begin{array}{ccc}
1 & -1 / 2 & -1 / 2 \\
0 & \sqrt{3} / 2 & -\sqrt{3} / 2
\end{array}\right]\left[\begin{array}{l}
\mathrm{Van} \\
\mathrm{Vbn} \\
\mathrm{Vcn}_{\mathrm{cn}}
\end{array}\right]} \\
& \overline{|V r e f|}=\sqrt{V d^{2}+V q^{2}}
\end{aligned}
$$

$\therefore \alpha=\tan ^{-1} \frac{V q}{V d}=\omega t=2 \pi f t$, where $\mathrm{f}=$ fundamental frequency

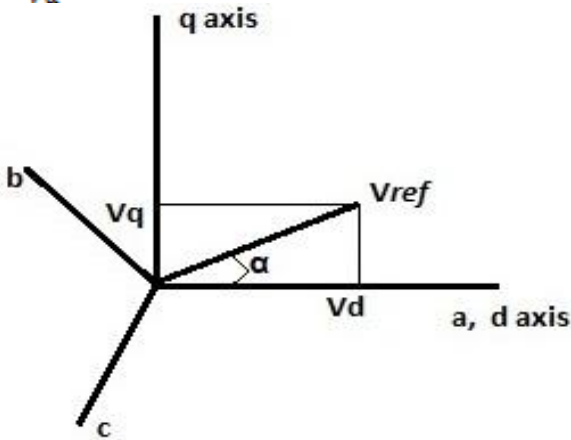

Step 2: Determine time duration T1, T2, T0

$$
\begin{gathered}
\mathrm{T} 1=\frac{\sqrt{\mathrm{a}} \mathrm{Tz} \cdot \sqrt{\text { Vref] }}}{\text { Vdc }}\left(\sin \frac{\mathrm{n} \pi}{\mathrm{a}} \cos \alpha-\cos \frac{\mathrm{n} \pi}{\mathrm{a}} \sin \alpha\right) \\
\mathrm{T} 2=\frac{\sqrt{\mathrm{a}} \mathrm{Tz} \cdot \sqrt{\mid \text { Vref } \mid}}{\mathrm{Vdc}}\left(\sin \left(\alpha+\frac{\mathrm{n}-1}{\mathrm{a}} \pi\right)\right. \\
\mathrm{T} 0=\mathrm{Tz}-\mathrm{T} 1-\mathrm{T} 2
\end{gathered}
$$

where, $\mathrm{n}=1$ through 6 (that is,Sector1 to 6 )

$$
0 \leq \alpha \leq 60^{\circ}
$$

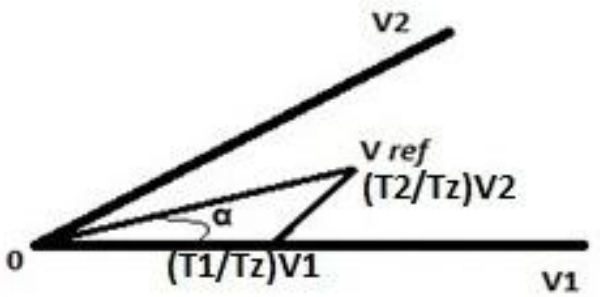

Figure 6: Reference vector as a combination of adjacent vectors at sector 1

Step3: Determine the switching time of each transistor ( $s$ to s2)

Space vector PWM switching pattern at each sector is as shown below.

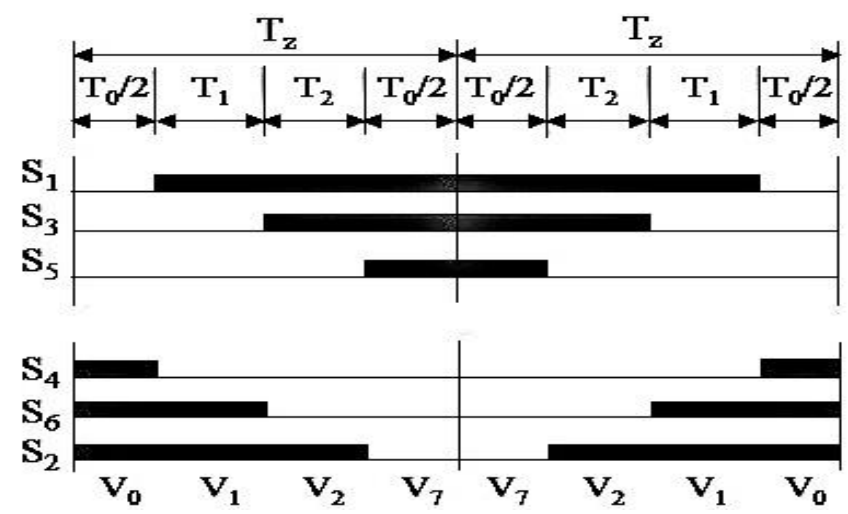

a) Sector 1
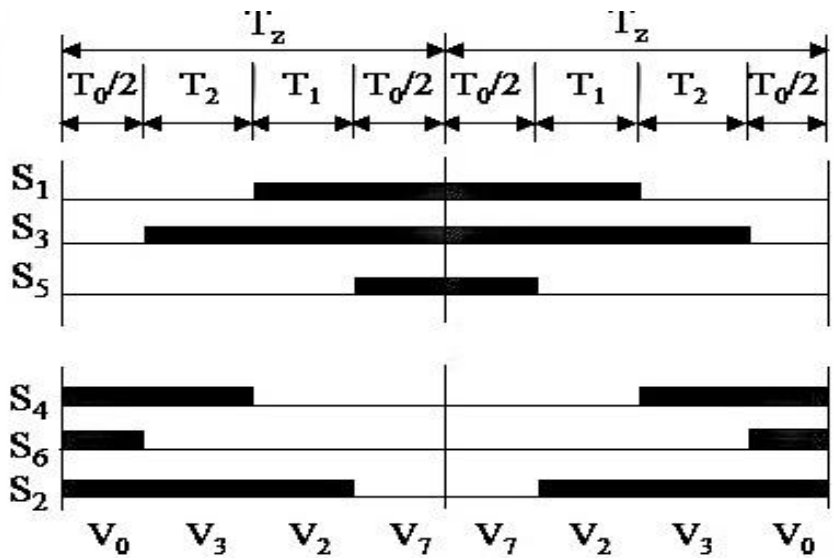

b) Sector 2 


\section{International Journal of Science and Research (IJSR) \\ ISSN (Online): 2319-7064}

Index Copernicus Value (2013): 6.14 $\mid$ Impact Factor (2014): 5.611

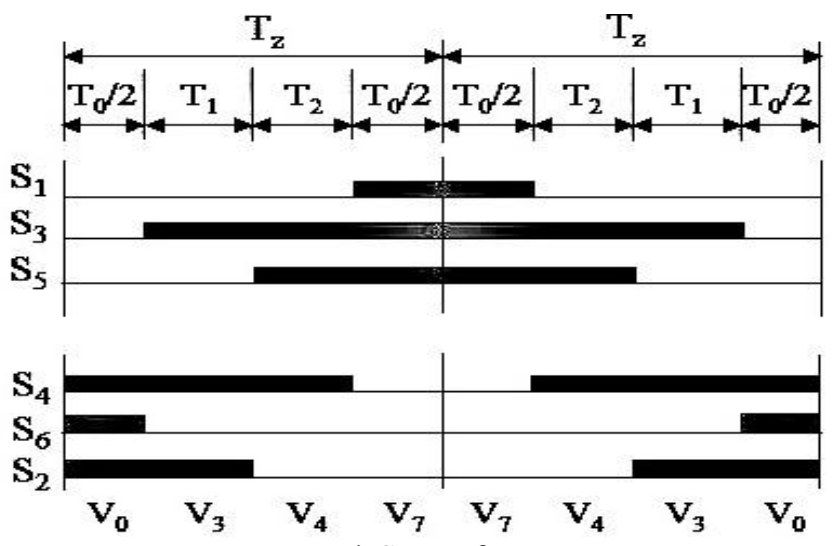

c) Sector 3

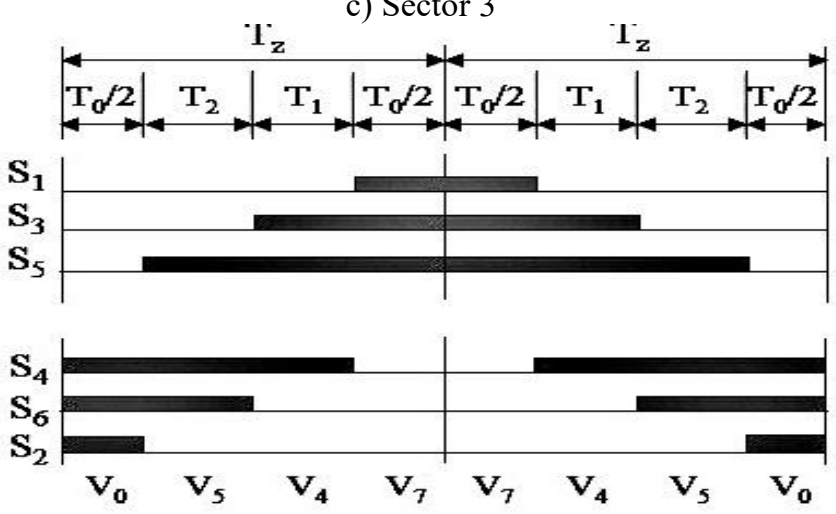

d) Sector 4

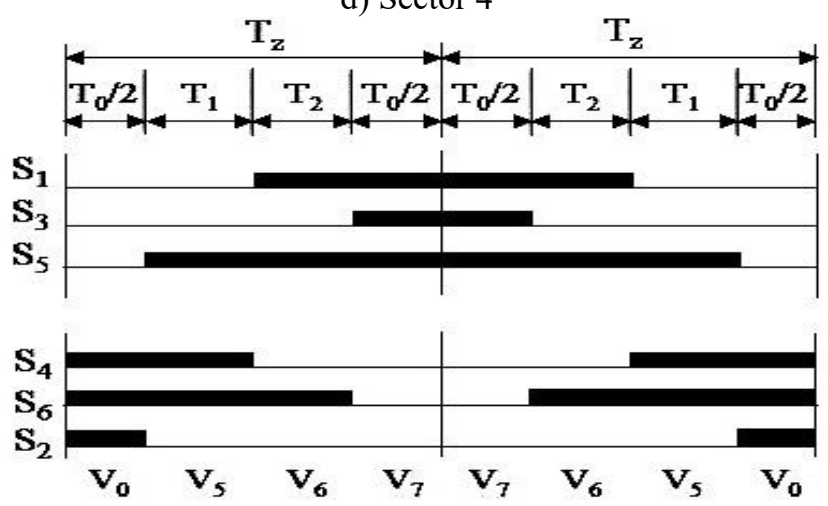

e) Sector 5
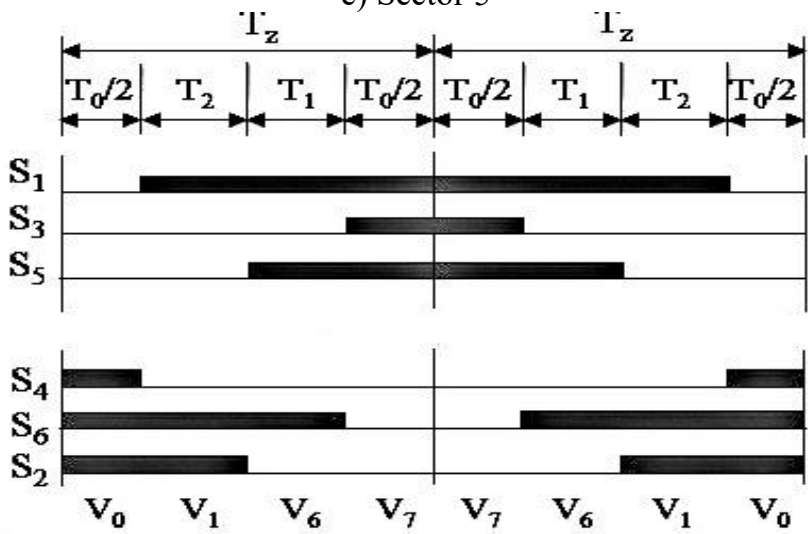

f) Sector 6

Figure6: The switching time at each sector is shown in table.

\section{Conclusion}

This gives better solution for power quality problems, because the power quality problems can have an effect on various customers. Most of the industries consist of large

Table: switching time calculation at each vector.

\begin{tabular}{|c|c|c|}
\hline Sector & $\begin{array}{c}\text { Upper Switches (S1, } \\
\text { S3, S5) }\end{array}$ & $\begin{array}{c}\text { Lower Switches (S4, } \\
\text { S6, S2) }\end{array}$ \\
\hline 1 & $\begin{array}{c}\mathrm{S} 1=\mathrm{T} 1+\mathrm{T} 2+\mathrm{T} 0 / 2 \\
\mathrm{~S} 3=\mathrm{T} 2+\mathrm{T} 0 / 2 \\
\mathrm{~S} 5=\mathrm{T} 0 / 2\end{array}$ & $\begin{array}{c}\mathrm{S} 4=\mathrm{T} 0 / 2 \\
\mathrm{~S} 6=\mathrm{T} 1+\mathrm{T} 0 / 2 \\
\mathrm{~S} 2=\mathrm{T} 1+\mathrm{T} 2+\mathrm{T} 0 / 2\end{array}$ \\
\hline 2 & $\begin{array}{c}\mathrm{S} 1=\mathrm{T} 1+\mathrm{T} 0 / 2 \\
\mathrm{~S} 3=\mathrm{T} 1+\mathrm{T} 2+\mathrm{T} 0 / 2 \\
\mathrm{~S} 5=\mathrm{T} 0 / 2\end{array}$ & $\begin{array}{c}\mathrm{S} 4=\mathrm{T} 2+\mathrm{T} 0 / 2 \\
\mathrm{~S} 6=\mathrm{T} 0 / 2 \\
\mathrm{~S} 2=\mathrm{T} 1+\mathrm{T} 2+\mathrm{T} 0 / 2\end{array}$ \\
\hline 3 & $\begin{array}{c}\mathrm{S} 1=\mathrm{T} 0 / 2 \\
\mathrm{~S} 3=\mathrm{T} 1+\mathrm{T} 2+\mathrm{T} 0 / 2 \\
\mathrm{~S} 5=\mathrm{T} 2+\mathrm{T} 0 / 2\end{array}$ & $\begin{array}{c}\mathrm{S} 4=\mathrm{T} 1+\mathrm{T} 2+\mathrm{T} 0 / 2 \\
\mathrm{~S} 6=\mathrm{T} 0 / 2 \\
\mathrm{~S} 2=\mathrm{T} 1+\mathrm{T} 0 / 2\end{array}$ \\
\hline 4 & $\begin{array}{c}\mathrm{S} 1=\mathrm{T} 0 / 2 \\
\mathrm{~S} 3=\mathrm{T} 1+\mathrm{T} 0 / 2 \\
\mathrm{~S} 5=\mathrm{T} 1+\mathrm{T} 2+\mathrm{T} 0 / 2\end{array}$ & $\begin{array}{c}\mathrm{S} 4=\mathrm{T} 1+\mathrm{T} 2+\mathrm{T} 0 / 2 \\
\mathrm{~S} 6=\mathrm{T} 2+\mathrm{T} 0 / 2 \\
\mathrm{~S} 2=\mathrm{T} 0 / 2\end{array}$ \\
\hline 5 & $\begin{array}{c}\mathrm{S} 1=\mathrm{T} 2+\mathrm{T} 0 / 2 \\
\mathrm{~S} 3=\mathrm{T} 0 / 2 \\
\mathrm{~S} 5=\mathrm{T} 1+\mathrm{T} 2+\mathrm{T} 0 / 2\end{array}$ & $\begin{array}{c}\mathrm{S} 4=\mathrm{T} 1+\mathrm{T} 0 / 2 \\
\mathrm{~S} 6=\mathrm{T} 1+\mathrm{T} 2+\mathrm{T} 0 / 2 \\
\mathrm{~S} 2=\mathrm{T} 0 / 2\end{array}$ \\
\hline 6 & $\begin{array}{c}\mathrm{S} 1=\mathrm{T} 1+\mathrm{T} 2+\mathrm{T} 0 / 2 \\
\mathrm{~S} 3=\mathrm{T} 0 / 2 \\
\mathrm{~S} 5=\mathrm{T} 1+\mathrm{T} 0 / 2\end{array}$ & $\begin{array}{c}\mathrm{S} 4=\mathrm{T} 0 / 2 \\
\mathrm{~S} 6=\mathrm{T} 1+\mathrm{T} 2+\mathrm{T} 0 / 2 \\
\mathrm{~S} 2=\mathrm{T} 2+\mathrm{T} 0 / 2\end{array}$ \\
\hline
\end{tabular}

\section{Matlab Simulation Results}

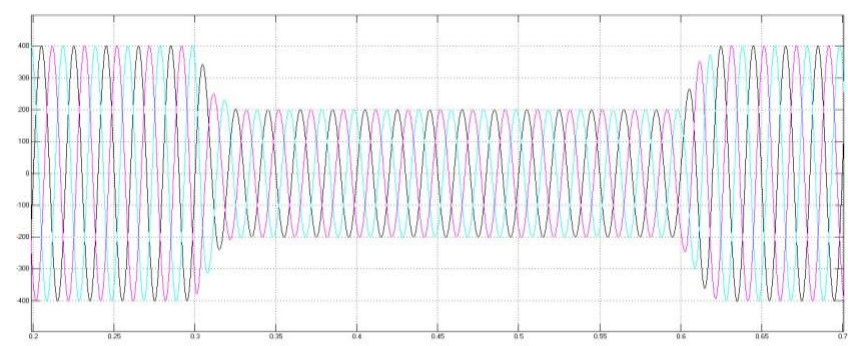

Figure 7: three phase voltage waveforms without DVR compensation

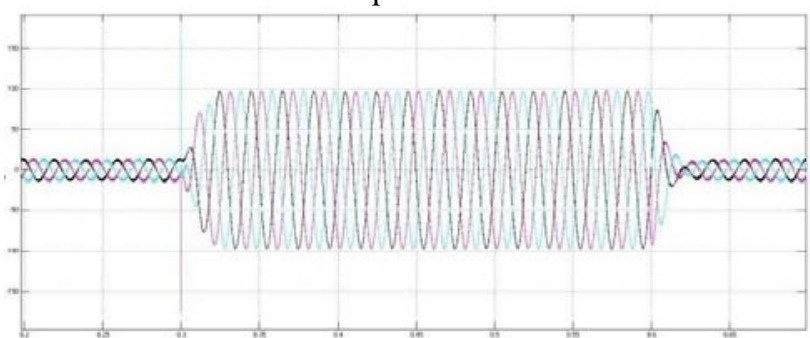

Figure 8: three phase voltage injected by DVR

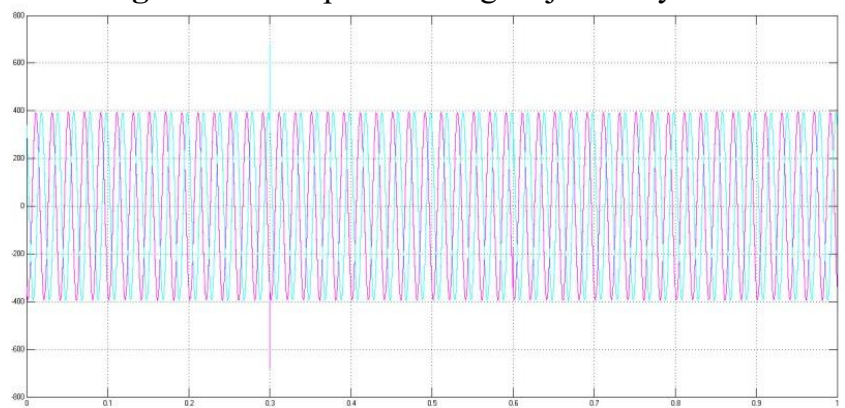

Figure 9: three phase voltage waveforms with DVR compensation 


\section{International Journal of Science and Research (IJSR) \\ ISSN (Online): 2319-7064}

Index Copernicus Value (2013): 6.14 | Impact Factor (2014): 5.611

number of power electronics devices and energy resourceful apparatus these are more susceptible to the unbalance in the input supply voltage. They can introduce the power quality problems. In these days issues of power quality is most important for customer. So for this custom power device, Dynamic Voltage Restorer (DVR) is used to mitigate these power quality problems, also it shows that the space vector pulse width modulation control technique is very good technique for dynamic voltage restorer as it plays an important role in mitigation of voltage sag, voltage swell, harmonics etc.

\section{References}

[1] H. Hingorani "Introducing custom power" IEEE spectrum, vol.32 no.6 June 1995 p 41 - 48.

[2] Benachaiba Chellali, FERDI Brahim, "Voltage Quality Improvement Using DVR," Electrical Power Quality and Utilizations, Journal Vol. XIV, No. 1, 2008

[3] M. Bollen. "Understanding Power Quality Problems, voltage sags and Interruptions." IEEE press, 1999.

[4] Ming Fang, Mister I. Gardiner, Andrew MacDougall, Granta A. Matheson, A novel series dynamic voltage restorer for distribution system, IEEE 1998

[5] C. Sankaran, "Power quality," (CRC Press, New York, 2001)

[6] C. Fitzer, M. Barnes and P. Green, "Voltage Sag Detection Technique for a Dynamic Voltage Restorer", IEEE Trans. Industry Applications, Vol. 40(1), Jan. 2004, pp. 203 - 212.

[7] S. Choi, J. Li and M. Vilathgamuwa, "A Generalized Voltage Compensation Strategy for Mitigating the Impacts of Voltage Sags/Swells", IEEE Trans. Power Delivery, Vol. 20(3),

[8] Nielsen, Newman, H. Nielsen, and F. Blaabjerg, "Control and testing of a dynamic voltage restorer (DVR) at medium voltage level," IEEE Trans. Power Electronics. vol. 19, no. 3, pp. 806-813, May 2004.

[9] J. G. Nielsen, "Design and Control of a Dynamic Voltage Restorer," Ph.D. dissertation, Institute of Energy Technology, Aalborg Univ., Aalborg, Denmark, 2002.

[10] Boonchiam P, and Mithulananthan N, "Understanding of Dynamic Voltage Restorers through MATLAB Simulation". Thammasat Int. J. Sc. Tech., Vol. 11, No. 3, July-Sept 2006.

[11] Yusuf K: "Industrial power quality problems Electricity Distribution. IEEE Conf. Pub1 No. 482, Vol: 2, 18-21 June 2001 Pages: 5 pp. vo1.2.

[12] K. C. Jana, S. K. Biswas and P. Thakura, "A simple and generalized space vector PWM control of cascaded Hbridge multilevel inverters", IEEE International conference on digital object identifier, (2006), pp. 12811286; Mumbai.

[13]M. Trabelsi, L. Ben-Brahim, T. Yokoyama, A. Kawamura, R. Kurosawa and T. Yoshino, "An improved SVPWM method for multilevel inverters", Power Electronics and Motion Control Conference, 2012 15th International Digital Object Identifier, (2012), LS5c.1-1 - LS5c.1-7; Novi Sad.

\section{Author Profile}

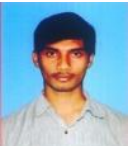

Shaik Babul Saheb was born in India in 1991, received B. Tech degree from JNTU, Kakinada and Pursuing M. Tech in QIS College of Engineering \& Technology, JNTUK in Power Systems. His field of interest is in FACT devices and Power systems

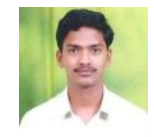

Nakka Narasimhrao received the B. Tech degree from JNTU Kakinada in the year 2010, M. Tech degree from JNTU Kakinada in the year 2013 and working as Assistant Professor in QIS College of Engineering \& Technology, Ongole. His interest in power quality improvement in deregulated power system 